\title{
Hard or Soft Science? Conceptualizing Educational Technology through a Lexical Bundle Analytical
}

\section{Approach}

\author{
Chih-Wei Kuo \\ Institute of Education, National Cheng Kung University, \\ No. 1, University Road, Tainan City 70101, Taiwan \\ E-mail: louielucky@hotmail.com
}

Received: December 25, 2016 Accepted: March 30, 2017 Published: April 9, 2017

doi:10.5296/elr.v3i1.10503

URL: http://doi.org/10.5296/elr.v3i1.10503

\begin{abstract}
An ongoing discussion on the disciplinary nature of educational technology has been taking place for years. Some view this discipline from the perspective of instructional design and implementation, whereas others conceptualize it from the perspective of media, tool, and system. This study examined educational technology from the perspective of language use by empirically investigating a special sequence of words, referred to as lexical bundles, in educational technology research articles. It aims to capture the distinctive nature of educational technology as soft technology and examine possible associations of educational technology with relevant disciplines. Employing a text analysis tool of AntConc 3.4.3, the researcher compiled a corpus encompassing 323 research articles from six journals with approximately 2.1 million words to identify lexical bundles. All identified bundles were analyzed and further compared with past relevant studies based on the number of different bundles, the content of bundles, and the grammatical structure of bundles. It was found that educational technology as an inter-discipline resembles much more soft science fields in terms of the content and structural categories of bundles. This study not only contributes to a better conceptual understanding of the nature of educational technology but offers a pedagogically beneficial bundle list for informing academic writing instruction in this field.
\end{abstract}

Keywords: Disciplinary nature of educational technology, Lexical bundle, Soft technology

\section{Introduction}

The term "educational technology" emerged and began officially as a discipline in the 1950s (Ellington, Percival, \& Race, 1993). Ever since its historical emergence, many efforts have 
been devoted to defining and conceptualizing what educational technology is (e.g., Latchem, 2014; Reiser, 2012). A continual discussion from different angles has been initiated to capture the nature of educational technology, such as the technology perspective (Lakhana, 2014), the practitioners perspective (Corbeil \& Corbeil, 2013), the systems perspective (Luppicini, 2005), the epistemological perspective (Czerniewicz, 2010), the critical perspective (Selwyn, 2007, 2010), and the socio-cultural perspective (Oliver, 2011). Notwithstanding this extensive discussion, it appears that much literature was not empirically informed and little research was undertaken from the perspective of language use. Recognizing these facts, the current study aims to conceptualize educational technology by analyzing the use of lexical bundles in journal articles. By carrying out a systematic linguistic analysis, we anticipate that the disciplinary nature of educational technology could be clarified and key concepts in this discipline could be provided. In the sections that follow, a brief review of lexical bundles is offered, followed by an introduction of lexical bundles in academic texts and subsequently a depiction of what educational technology is.

\subsection{Definition and Characteristics of Lexical Bundles}

Appearing first in the Longman Grammar of Spoken and Written English (Biber, Johansson, Leech, Conrad, \& Finegan, 1999), lexical bundles refer to a progressive succession of individual words occurring with a comparatively high frequency in spoken and written language (Biber \& Barbieri, 2007). For instance, thank you very much is a recurrent spoken-form bundle in daily conversation to express one's utmost gratitude to the addressed person, while as can be seen is a common written-form bundle in academic prose to make readers aware of the research results shown in tables or figures. There are a number of parallel terms for denoting similar notions of lexical bundles in pertinent literature, such as clusters (Hyland, 2008a, b), n-grams (Stubbs, 2007), lexical phrases (Li \& Schmitt, 2009), prefabricated patterns (Granger, 1998), formulaic sequences (Simpson-Vlach \& Ellis, 2010), sentence stems (Pawley \& Syder, 1983), extended collocations (Cortes, 2004), and multi-word expressions (Rayson, 2008).

Lexical bundles do not occur randomly but can be identified empirically by using computer software. To be recognized as lexical bundles, they must meet two key criteria: (a) frequency: the number of bundles occurring in a text; (b) range: the distribution of bundles in a number of text. The frequency can be set differently, varying from 10 to 50 times per million words (Biber, Conrad, \& Cortes, 2004; Breeze, 2013; Grabowski, 2015; Hyland, 2008a; Simpson-Vlach \& Ellis, 2010). The most extensively adopted frequency is 20 times per million words (e.g., Biber et al., 1999; Cortes, 2004; Jalali, Rasekh, \& Rizi, 2008; Liu, 2012; Wei \& Lei, 2011). The range, on the other hand, is applied to establish representativeness, thereby avoiding idiosyncrasies associated with particular texts. Existing bundle studies determined range using either a particular number across all texts (e.g., Biber \& Barbieri, 2007; Chen \& Baker, 2010; Liu, 2012) or a percentage (e.g., Jalali, et al., 2008; Hyland, 2008b). Demirel and Hesamoddin, (2013), for example, set the criterion that bundles had to occur at least across four different texts in their corpus, while Jalali et al. (2008) used bundles that distribute in at least ten percent of the texts. Different selection criteria are also related to varying corpora sizes compiled and research purposes to be accomplished, which may imply 
that setting the bundle frequency along with range is somewhat arbitrary (Csomay, 2013; Hyland, 2008b).

With a high frequency of occurrences, lexical bundles are characterized by structurally incomplete units, semantically transparent representations, and non-fixed forms (Biber \& Barbieri, 2007; Biber et al., 1999; Cortes, 2004). First, most bundle structures appear in a rather fragmented way and tend to bridge over two separate syntactic units, usually with an incomplete structural unit incorporated into a complete one (Biber et al., 1999). Biber et al. (1999), in their large-scale investigation of everyday discourse, found that $95 \%$ of the lexical bundles in academic prose and $85 \%$ in conversation are structurally incomplete. Instances addressing this phenomenon include the fact that the, in the context of, and the nature of the. The second feature of bundles is semantic transparency, a characteristic that one can decode the bundle meaning by simply analyzing component elements. For example, the meaning of the bundle of purpose of the study can be derived if one understands the meaning of the four component words. This is quite distinct from idioms which are semantically opaque and the meanings of which are difficult to derive from the literal meanings of the components (Wei \& Lei, 2011). The idiomatic meaning of beat around the bush is neither associated with beat nor with bush. Third, the bundle form is determined by the sequence of words identified. For instance, the four-word bundle of purpose of the study belongs to the grammatical category of noun phrase + of, while the six-word bundle of for the purpose of the study is the category of prepositional phrase + of. The non-fixed length of bundle units refers to the fact that researchers may choose to identify varying lengths of bundles for different research purposes. Four-word bundles are the most often explored form since, on the one hand, they are far more common than five-word and six-word bundles and, on the other hand, they offer a much clearer structure than three-word bundles (Csomay, 2013; Biber et al., 1999; Hyland, 2008a). The current study also targets four-word bundles as the research focus.

\subsection{Lexical Bundles in Academic Texts}

Lexical bundles constituting critical building blocks of language prevail in academic texts. Erman and Warren (2000), for example, explored the average proportion of recurrent word combinations in their compiled academic texts and found that the recurrent word combinations account for $58.6 \%$ of the spoken texts and $52.3 \%$ of the written texts. The high frequency of these recurrent word expressions suggests that the use of lexical bundles in academic texts involves not only the linguistic repertoires of scholars but the underlying structure of disciplinary knowledge. Hyland (2008b) noted that lexical bundles can serve as a tool to help assert the identity of disciplinary community and demonstrate the ways in which disciplinary members communicate with each other. Disciplinary variations could be empirically found by various ways in which lexical bundles are exploited, including the total number of bundles, the structural forms of bundles, and the rhetorical functions of bundles (Alipour, \& Zarea, 2013; Kashiha \& Heng, 2014a, b; Jalali, 2014). Cortes (2004), for instance, conducted a comparative study to examine lexical bundles in biology and history, finding that the total number of bundles in biology (109 bundles) is more than twice of the number in history ( 54 bundles). The study also revealed that history relies mainly on a limited number of structural categories of noun phrase bundles and prepositional phrase bundles, compared to 


\section{Macrothink}

biology (Cortes, 2004). Hyland (2008b), comparing four disciplines of applied linguistics, business studies, electrical engineering, and biology, demonstrated that electrical engineering uses a considerably higher number of different bundles (213 bundles) than that in the other three disciplines. Hyland also found that the structure of passive bundles occurs in a high frequency in hard science (i.e., electrical engineering, and biology), but has a low prevalence in soft science (i.e., applied linguistics and business studies). Jalali et al. (2008) inspected the use of lexical bundles in applied linguistics in terms of the total number and structural categories, finding that this discipline has a similar total number of bundles and employs a much lower percentage of passive bundles, both results consistent with Hyland (2008b). These findings suggest that lexical bundles as part of the academic discourse are not expressed in a "monolithic entity" (Gotti, 2009, p. 10) but reveals the underlying nature of specific disciplines, a single discipline or even a group of disciplines sharing similar features. The distinctive disciplinary nature and culture reflect inherent epistemological beliefs, intellectual values, and cognitive knowledge in various micro and macro disciplinary communities (Becher \& Trowler, 2001).

A series of efforts have been spent in investigating lexical bundles to uncover disciplinary characteristics. The disciplines examined cover a wide range of long-established disciplines, including applied linguistics (Hyland, 2008b; Jalali et al., 2008), law (Breeze, 2013), history (Cortes, 2004), business studies (Hyland, 2008b), physics (Alipour, \& Zarea, 2013), computer engineering (Alipour \& Zarea, 2013), electrical engineering (Chen \& Xiao, 2015; Hyland, 2008b), biology (Cortes, 2004; Hyland, 2008b), pharmacy (Grabowski, 2015), and medicine (Jalali, Moini, \& Arani, 2015). These disciplines fall into either hard science (e.g., electrical engineering, physics, biology, and medicine) or soft science (e.g., applied linguistics, politics, and business studies), which is a rigid dichotomy. Nevertheless, educational technology, eclectic in nature (Ajelabi, 2006; Davies \& Schwen, 1971), subsumes concepts from both education and technology, bearing in itself relatedness to both hard science and soft science. Given that educational technology has inherent hybrid nature, it would be a worthwhile endeavor to explore its disciplinary culture by means of an empirical study on the use of lexical bundles and from the perspective of applied linguistics. In other words, what types of lexical bundles are frequently employed in educational technology? Can the bundles in educational technology characterize or reflect the disciplinary nature of this specific research field?

\subsection{Disciplinary Nature of Educational Technology}

The disciplinary nature of educational technology derives its underpinnings primarily from education and technology (Mangal \& Mangal, 2009). Education as one disciplinary area in soft science is "functional and utilitarian, concerned with enhancement of professional practice and results in protocols/procedures (Becher \& Trowler, 2001, p. 36);" it aims to help one grow, upgrade, expand, and transform in the aspects of knowledge, thoughts, skills, and attitudes so as to become a good problem solver (Spector, Johnson, \& Young, 2014). Technology, on the other hand, affiliated to hard science, is "purposive and pragmatic, concerned with mastery of physical environment and results in products/techniques" (Becher, $\&$ Trowler, 2001, p. 36). It involves the application of tangible devices or systematic 


\section{Ml Macrothink}

knowledge to accomplish a practical purpose, thereby bringing benefits to society (Spector et al., 2014). Educational technology, incorporating the two, is the study using technological resources or technological knowledge for the purpose of learning in the educational context (Loveland, 2012).

Educational technology in its first emergence was regarded as identical to media with a launch of audiovisual education movement (Newby, Stepich, Lehman, \& Russell, 2006); audiovisual materials, such as films, pictures, and stereopticon slides were considered synonymous with educational technology. Later, with the advent of the electronic and mass communication revolution, educational technology was linked with the use of tape-recorders, radio, television, and computer-assisted resources (Mangal \& Mangal, 2009). The conception of educational technology changed in the period of 1960s to 1980s. It is no longer considered as merely audiovisual aids and hardware materials but instead understood as a process in which instructors design, implement, and evaluate (Association for Educational Communications and Technology, 1977). Such a conception departs from a traditional view seeing educational technology as a physical means to a systematic process underscoring instructional design procedure. A recent definition, proposed by the Association for Educational Communications and Technology (AECT) in 2008, suggests that "educational technology is the study and ethical practice of facilitating learning and improving performance by creating, using, and managing appropriate technological processes and resources" (Januszewski \& Molenda, 2008, p. 1). This definition concludes previous conceptions, highlights both aspects of systematic processes and technological resources, and indicates the main purpose of educational technology-improving the efficiency of the teaching and learning process (Reiser, 2012).

The role that technology plays in educational technology can be viewed as a means to the instructional end. A distinction is made between hard technology and soft technology. Hard technology is primarily concerned with physical products that engineers or scientists attempt to develop, such as computer equipment, communication devices, and technology tools (Luppicini, 2005). Soft technology, the technology in educational technology, refers to the intellectual process in which individuals apply organized knowledge to accomplish educational goals (Januszewski \& Molenda, 2008). It is value-laden and emphasizes the meaning of who uses technology and the manner in which technology is used (McGinn, 1978). It highlights intellectual, environmental, social, and cultural factors in its realization (Lakhana, 2014; Luppicini, 2005). These include practices of setting learning objectives, implementing instructional design, selecting media and resources, managing systems, and evaluating learning outcomes.

In summary, the conception of educational technology constantly changes and evolves as time goes by (Ellington et al., 1993; Lakhana, 2014; Luppicini, 2008; Reiser, 2012). The historical development of the conception of educational technology shifts its focus from the early emphasis on simply using media, materials as well as tools but playing down the role of humans to the recent emphasis on adopting a systematic perspective and giving equal weight to both human and non-human resources. The contemporary conception highlights a macro-level and comprehensive explanation of educational technology. Since past studies 
seldom examined the notion of educational technology from the perspective of language use, an exploration of lexical bundles might enlighten the conceptual aspects of educational technology. The current study thus attempts to take a lexical bundle analytical approach to empirically investigating whether we can obtain a similar conclusion as the contemporary conception of educational technology suggests.

\subsection{Purpose of the Study and Research Questions}

Based on the discussions in the above sections, this study aims to investigate the extent to which the use of lexical bundles can reveal the nature of educational technology as an inter-discipline. In particular, it focuses on identifying the most frequently used four-word lexical bundles, finding out the most prevalent structural categories of bundles in educational technology, as well as comparing and contrasting the similarities and differences between educational technology and previously researched disciplines in the use of lexical bundles. By making cross-disciplinary comparisons in lexical bundles, we hope not only to provide insights into the possible association of educational technology with hard or soft science but also to clearly clarify the disciplinary nature of educational technology. Three research questions are formulated in the current study, as follows:

1). What are the most frequent four-word lexical bundles in educational technology research articles?

2). What are the structural features of the four-word lexical bundles in educational technology research articles?

3). To what extent can the use of bundles reveal the nature of educational technology?

\subsection{Importance of the Study}

The importance of this study is twofold. First, the disciplinary nature of educational technology is properly clarified through a systematic analysis of lexical bundles. Findings of this study can offer empirical evidence on the basis of which the conceptual aspect and the disciplinary orientation of educational technology are well elucidated. Second, what has been disclosed in this empirical study provides a beneficial list of the lexical bundles in the discipline of educational technology. An empirically derived study, as Simpson-Vlach \& Ellis (2010) noted, could be pedagogically valuable so as to benefit academic writing instruction and to inform curriculum design.

\section{Method}

\subsection{The Corpus}

The corpus compiled in the study consists of 323 research articles (RAs), amounting to 2,163,545 word forms, from six representative journals of educational technology published in 2013: Computers \& Education, British Journal of Educational Technology, Educational Technology \& Society, Journal of Computer-Assisted Learning, Australasian Journal of Educational Technology, and Educational Technology Research and Development. These six journals were chosen partly because they are internationally leading journals in educational 
technology and partly because they publish RAs on a wide variety of issues in the discipline, such as mobile and ubiquitous learning, computer-supported collaborative learning, personalized technology-enhanced learning, digital game-based learning, e-assessment, big data in education, artificial intelligence in education, development of online learning and management system, and so on. All RAs were derived from the websites of the journals. The non-textual parts in each RA (e.g., tables, figures, references, charts, notes, appendixes, and page numbers) were removed to ensure that all of the compiled data can be processed by the computer program. Table 1 shows the complete information of the corpus, including the number of texts and number of words.

Table 1. Corpus composition

\begin{tabular}{lll}
\hline Journal & No. of texts & No. of words \\
\hline Computers \& Education & 59 & 462,880 \\
British Journal of Educational Technology & 70 & 404,415 \\
Educational Technology \& Society & 54 & 292,549 \\
Journal of Computer-Assisted Learning & 36 & 241,333 \\
Australasian Journal of Educational Technology & 60 & 391,593 \\
Educational Technology Research and Development & 44 & 370,775 \\
Total & 323 & $2,163,545$ \\
\hline
\end{tabular}

\subsection{The Computer Program and the Structural Analysis of Bundles}

After the compilation of the corpus, the next step was to employ an appropriate computer program to identify lexical bundles. The computer program employed in the current study was AntConc 3.4.3. (Anthony, 2014), a free and open-source text analysis tool by which users can extract lexical bundles by setting specific criteria of frequency and desired bundle size. The present research aims to clarify the nature of educational technology and define its disciplinary orientation by comparing the research findings with those in past studies. Two important disciplinary studies by Hyland (2008b), which was based on a 3.5-million-word corpus, and Jalali et al. (2008), which was based on a 1.2-million-word corpus were targeted for a comparison since they investigated the use of lexical bundles in a number of hard and soft science fields, including applied linguistics, business studies, electrical engineering, and biology. Comparing educational technology with those hard and soft science fields may help us better understand whether and how educational technology, in terms of its underlying nature and the disciplinary orientation, is more geared towards hard science or soft science. To draw a parallel comparison, four-word bundles were targeted and the cut-off frequency must occur at least 20 times per million words together with in at least ten percent of all texts. Such criteria were consistent with those set in Hyland (2008b) and Jalali et al. (2008). 


\section{Macrothink}

Education and Linguistics Research

ISSN 2377-1356 2017, Vol. 3, No. 1

After all of the lexical bundles were identified, the structural analysis ensued. The identified bundles, following Biber et al.'s (1999) taxonomy with twelve structural categories (see Table 2), were analyzed by two doctoral students who specialize in the field of educational technology and are familiar with the method of corpus analysis. The intercoder agreement reached $94.4 \%$.

Table 2. Structural categories of lexical bundles

\begin{tabular}{|c|c|}
\hline Structural categories & Examples \\
\hline Noun phrase + of & the results of the, the use of the, the effectiveness of the \\
\hline Other noun phrases & the students in the, the extent to which, a positive effect on, \\
\hline Prepositional phrase + of & in the context of, on the basis of, at the end of \\
\hline Other prepositional phrases & on the other hand, in line with the, in a way that \\
\hline $\begin{array}{l}\text { Passive }+ \text { prepositional phrase } \\
\text { fragment }\end{array}$ & are shown in table, is based on the, used in this study \\
\hline Anticipatory $i t+$ verb/adjective & it is possible to, it is important to, it is necessary to \\
\hline $\begin{array}{l}\text { Be }+ \text { noun/adjectival phrase } \\
(\text { Verb phrase }+ \text { ) that clause } \\
\text { fragment }\end{array}$ & $\begin{array}{l}\text { are more likely to, be due to the, is based on the } \\
\text { that there was a, that there is a, the results showed that }\end{array}$ \\
\hline $\begin{array}{l}\text { (Verb/adjective }+ \text { ) to-clause } \\
\text { fragment }\end{array}$ & can be used to, are more likely to, to be able to \\
\hline Adverbial clause fragment & as shown in figure, as shown in table \\
\hline Pronoun/noun phrase $+b e$ & this study is to, this study was to \\
\hline Others & as well as the, and the use of \\
\hline
\end{tabular}

\section{Results}

\subsection{The Most Frequent Four-word Lexical Bundles in Educational Technology RAs}

Setting the criteria of 20 times per million words as the cut-off frequency along with ten percent of distribution throughout the texts, the present study yielded 125 different bundles, with a total frequency of 10,196 occurrences of these 125 bundles. $86 \%$ of the bundles occur over 50 times, and 18\% over 100 times. The bundle of on the other hand is the most frequently used, with a frequency as high as 314 occurrences, while the bundle of the analysis of the is the least frequently used, with a relatively low frequency of 44 occurrences. A complete list of the bundles is presented in the appendix 1. Table 3 shows the top 20 lexical bundles. 
Table 3. The top 20 lexical bundles in educational technology RAs

\begin{tabular}{|c|c|c|c|}
\hline Rank & Lexical bundles & Frequency & Range* \\
\hline 1 & on the other hand & 314 & 154 \\
\hline 2 & the results of the & 236 & 123 \\
\hline 3 & at the end of & 222 & 103 \\
\hline 4 & the end of the & 213 & 111 \\
\hline 5 & the use of the & 209 & 98 \\
\hline 6 & as well as the & 205 & 130 \\
\hline 7 & in the context of & 190 & 114 \\
\hline 8 & the students in the & 168 & 66 \\
\hline 9 & at the same time & 165 & 110 \\
\hline 10 & in the form of & 154 & 99 \\
\hline 11 & as shown in table & 151 & 75 \\
\hline 12 & in terms of the & 143 & 89 \\
\hline 13 & as a result of & 131 & 77 \\
\hline 14 & the results of this & 129 & 82 \\
\hline 15 & on the basis of & 128 & 61 \\
\hline 16 & it is important to & 127 & 89 \\
\hline 17 & can be used to & 124 & 83 \\
\hline 18 & in this study the & 116 & 80 \\
\hline 19 & the extent to which & 110 & 62 \\
\hline 20 & the beginning of the & 109 & 61 \\
\hline
\end{tabular}

*Range refers to the number of texts where a lexical bundle occurs.

\subsection{Structural Analysis of Four-word Lexical Bundles in Educational Technology RAs}

Table 4 shows the results of the structural analysis of bundles. As can be seen, the structural category of noun phrase + of has the highest percentage $(25.64 \%)$, followed in a descending order by prepositional phrase + of $(22.09 \%)$, other prepositional phrases $(20.93 \%)$, and other noun phrases $(6.76 \%)$. The four categories together account for three-fourths of all occurrences. The remaining one-fourth is made up of the other eight structural categories, each of which constitutes a very small percentage of less than $5 \%$. 
Table 4. Structural analysis of lexical bundles in educational technology

\begin{tabular}{|c|c|c|c|c|}
\hline Structural categories & $\begin{array}{l}\text { No. } \\
\text { bundles }\end{array}$ & of & $\begin{array}{l}\text { Overall } \\
\text { frequency }\end{array}$ & Percentage \\
\hline Noun phrase $+o f$ & 31 & & 2614 & $25.64 \%$ \\
\hline Prepositional phrase + of & 25 & & 2252 & $22.09 \%$ \\
\hline Other prepositional phrases & 26 & & 2134 & $20.93 \%$ \\
\hline Other noun phrases & 8 & & 689 & $6.76 \%$ \\
\hline$($ Verb/adjective + ) to-clause fragment & 7 & & 505 & $4.95 \%$ \\
\hline$($ Verb phrase + ) that clause fragment & 8 & & 465 & $4.56 \%$ \\
\hline Passive + prepositional phrase fragment & 5 & & 445 & $4.36 \%$ \\
\hline Others & 4 & & 358 & $3.51 \%$ \\
\hline Anticipatory $i t+$ verb/adjective & 5 & & 342 & $3.39 \%$ \\
\hline Pronoun/noun phrase $+b e$ & 3 & & 187 & $1.83 \%$ \\
\hline Adverbial clause fragment & 2 & & 139 & $1.36 \%$ \\
\hline $\mathrm{Be}+$ noun/adjectival phrase & 1 & & 66 & $0.65 \%$ \\
\hline Total & 125 & & 10196 & $100 \%$ \\
\hline
\end{tabular}

Noun phrase $+o f$, as the most frequent structural category, is formed usually by a head noun as the center of bundle, preceded by such modifiers as articles and determiners and followed by an incomplete embedded of-phrase (e.g., of the, of a). The most prominent prevailing pattern is "the + head noun + of + the." Instances using this pattern include the results of the, the end of the, the use of the, the effect of the, the design of the, and so forth. In these instances, the head noun is enclosed by the in the beginning and of the in the end. The head nouns within these bundles are mostly abstract nouns, but not necessarily discipline-specific topic words. They perform a wide range of functions, such as description of research procedures (e.g., the use of the, the design of the, the development of the, the implementation of the), quantifications (e.g., the majority of the, the rest of the), and label of the location (e.g., the end of the, the beginning of the).

Apart from noun phrases, prepositional phrases are another important element in bundles, considering that the second and the third structural categories constitute $43 \%$ of all bundles. A number of prepositional phrases have been found, such as in-phrases, on-phrases, at-phrases, of-phrases, for-phrases, through-phrases, and within-phrases. Of these phrases, in-phrases occur most extensively. In the form of, in the field of, in terms of the, in addition to the, in the present study, and in a way that are some examples of incorporating in-phrases into bundles.

\subsection{Comparison between the Present Study and Previous Studies}

To reveal possible bundle similarities and differences between disciplines, a cross-discipline 
comparison was made. The findings of this study were compared and contrasted with two past studies: Hyland (2008b), a multi-disciplinary study on lexical bundles in four disciplines - electrical engineering, business studies, applied linguistics, and biology, and Jalali et al. (2008), a study on lexical bundles in applied linguistics. Table 5 lists the results of the two studies as well as the present study.

Table 5. Cross-discipline comparison of lexical bundles

\begin{tabular}{|c|c|c|c|c|c|c|}
\hline Discipline & $\begin{array}{l}\text { Electrical } \\
\text { Engineering } \\
\text { (Hyland) }\end{array}$ & $\begin{array}{l}\text { Business } \\
\text { Studies } \\
\text { (Hyland) }\end{array}$ & $\begin{array}{l}\text { Biology } \\
\text { (Hyland) }\end{array}$ & $\begin{array}{l}\text { Applied } \\
\text { Linguistics } \\
\text { (Hyland) }\end{array}$ & $\begin{array}{l}\text { Applied } \\
\text { Linguistics } \\
\text { (Jalali) }\end{array}$ & $\begin{array}{l}\text { Educational } \\
\text { Technology } \\
\text { (this study) }\end{array}$ \\
\hline $\begin{array}{l}\text { No. } \\
\text { different } \\
\text { bundles }\end{array}$ & 213 & 144 & 131 & 141 & 125 & 125 \\
\hline \multicolumn{7}{|l|}{$\begin{array}{l}\text { Structural } \\
\text { categories }\end{array}$} \\
\hline $\begin{array}{l}\text { Noun phrase }+ \\
\text { of }\end{array}$ & $22.3 \%(2)$ & $28.5 \%(1)$ & $23.7 \%(2)$ & $22.9 \%(2)$ & $22.89 \%(2)$ & $25.64 \%(1)$ \\
\hline $\begin{array}{l}\text { Prepositional } \\
\text { phrase }+ \text { of }\end{array}$ & $7.9 \%$ & $16.0 \%(3)$ & $9.2 \%$ & $19.9 \%(3)$ & $29.69 \%(1)$ & $22.09 \%(2)$ \\
\hline $\begin{array}{l}\text { Other } \\
\text { prepositional } \\
\text { phrases }\end{array}$ & $11.6 \%(3)$ & $19.7 \%(2)$ & $13.7 \%(3)$ & $24.4 \%(1)$ & $19.26 \%(3)$ & $20.93 \%(3)$ \\
\hline $\begin{array}{l}\text { Other noun } \\
\text { phrases }\end{array}$ & $10.8 \%(4)$ & $12.4 \%(4)$ & $9.4 \%(4)$ & $9.6 \%(4)$ & $10.49 \%(4)$ & $6.76 \%(4)$ \\
\hline $\begin{array}{l}\text { (Verb/adjective } \\
+\quad \text { ) to-clause } \\
\text { fragment }\end{array}$ & - & - & - & - & - & $4.95 \%$ \\
\hline $\begin{array}{l}\text { (Verb phrase } \\
+ \text { ) that clause } \\
\text { fragment }\end{array}$ & - & - & - & - & - & $4.56 \%$ \\
\hline $\begin{array}{l}\text { Passive }+ \\
\text { prepositional } \\
\text { phrase } \\
\text { fragment }\end{array}$ & $29.8 \%(1)$ & $9.0 \%$ & $31.3 \%(1)$ & $6.9 \%$ & $2.34 \%$ & $4.36 \%$ \\
\hline Others & $9.2 \%$ & $9.9 \%$ & $6.4 \%$ & $10.7 \%$ & $8.22 \%$ & $3.51 \%$ \\
\hline $\begin{array}{l}\text { Anticipatory it } \\
+\end{array}$ & $8.4 \%$ & $4.5 \%$ & $6.3 \%$ & $5.6 \%$ & $5.46 \%$ & $3.39 \%$ \\
\hline
\end{tabular}


verb/adjective

\begin{tabular}{|c|c|c|c|c|c|c|}
\hline $\begin{array}{l}\text { Pronoun/noun } \\
\text { phrase }+b e\end{array}$ & - & - & - & - & - & $1.83 \%$ \\
\hline $\begin{array}{l}\text { Adverbial } \\
\text { clause } \\
\text { fragment }\end{array}$ & - & - & - & - & - & $1.36 \%$ \\
\hline $\begin{array}{l}\mathrm{Be}+ \\
\text { noun/adjectival } \\
\text { phrase }\end{array}$ & - & - & - & - & $1.65 \%$ & $0.65 \%$ \\
\hline
\end{tabular}

The comparison revealed several interesting results. First, concerning the number of different bundles, electrical engineering has a by-far larger number (213) than the other disciplines, including business studies (144), applied linguistics (141 and 125, respectively), biology (131), and educational technology (125), while these other disciplines do not differ greatly from each other. Educational technology, as shown in this study, holds a much smaller number of different bundles than electrical engineering.

Second, the cross-discipline structural comparison, as shown in Table 5, showed that the prevailing structural categories of lexical bundles in educational technology are similar to those in business studies and applied linguistics. Four bundle structures, namely, noun phrase $+o f$, prepositional phrase $+o f$, prepositional phrase $+o f$, and other prepositional phrases, recur in the RAs in these three disciplines, though in different rankings. The four categories together account for over three-fourths of the total frequency in each of the three disciplines. In comparison, the top four bundle categories in biology and electrical engineering are: passive + prepositional phrase fragment, noun phrase $+o f$, other prepositional phrases, and other noun phrases. The greatest difference is the category of passive + prepositional phrase fragment, which is not often used in the three previously mentioned disciplines (i.e., $4.36 \%$ in educational technology, $6.9 \%$ and $2.34 \%$ in applied linguistics, and $9.0 \%$ in business studies) but frequently employed in biology (31.3\%) and electrical engineering $(29.8 \%)$. This finding may distinguish educational technology from such hard science disciplines as electrical engineering and biology.

To look further into the similarities of educational technology with other disciplines, the content of the identified bundles in each discipline was compared with each other and analyzed. Since Hyland's (2008b) study offers only the top 50 bundles, not a complete list, the top 50 bundles from each of the other studies were drawn for comparison. The result of the cross-discipline analysis revealed that $50 \%$ of the top 50 bundles in educational technology are overlapping with those in applied linguistics (Jalali et al., 2008), 40\% are overlapping with those in business studies and applied linguistics (Hyland, 2008b), and 34\% with biology, but only $20 \%$ with electrical engineering. Table 6 presents a list of the top 50 bundles in educational technology, applied linguistics, and electrical engineering. 
Table 6. Cross-discipline comparison of the top 50 lexical bundles

\begin{tabular}{|c|c|c|c|}
\hline $\begin{array}{l}\text { Educational } \\
\text { technology }\end{array}$ & $\begin{array}{l}\text { Applied } \\
\text { Linguistics(Jalali) }\end{array}$ & $\begin{array}{l}\text { Applied } \\
\text { Linguistics(Hyland) }\end{array}$ & $\begin{array}{l}\text { Electrical } \\
\text { engineering(Hyland) }\end{array}$ \\
\hline on the other hand* & on the other hand $* *$ & on the other hand $* *$ & on the other hand** \\
\hline the results of the & in the case of & at the same time & as shown in figure \\
\hline at the end of & at the same time & in terms of the & in the case of \\
\hline the end of the & the extent to which & on the basis of & is shown in figure \\
\hline$\underline{\text { the use of the }}$ & the end of the & in relation to the & it can be seen \\
\hline as well as the & in the context of & in the case of & as shown in fig \\
\hline in the context of & the use of the & in the present study & is shown in fig \\
\hline$\underline{\text { the students in the }}$ & at the end of & the end of the & can be seen that \\
\hline at the same time & as well as the & the nature of the & can be used to \\
\hline in the form of & in terms of the & in the form of & the performance of the \\
\hline as shown in table & on the basis of & as well as the & as a function of \\
\hline in terms of the & it is important to & at the end of & is based on the \\
\hline$\underline{\text { as a result of }}$ & as a result of & the fact that the & with respect to the \\
\hline the results of this & the ways in which & in the context of & is given by equation \\
\hline on the basis of & to be able to & is one of the & the effect of the \\
\hline it is important to & in the present study & in the process of & the magnitude of the \\
\hline$\underline{\text { can be used to }}$ & on the part of & the results of the & at the same time \\
\hline in this study the & in the form of & in terms of their & in this case the \\
\hline$\underline{\text { the extent to which }}$ & on the one hand & to the fact that & it is found that \\
\hline the beginning of the & a wide range of & in the sense that & the size of the \\
\hline results of this study & as a second language & the relationship between the & be seen that the \\
\hline at the beginning of & at the beginning of & of the hong kong & the accuracy of the \\
\hline$\underline{\text { in the case of }}$ & the results of the & at the beginning of & as well as the \\
\hline that the use of & the fact that the & the role of the & the same as the \\
\hline the quality of the & the nature of the & of the present study & is one of the \\
\hline to the use of & in the process of & as a result of & a function of the \\
\hline on the use of & in the field of & one of the most & as a result the \\
\hline to be able to & can be seen in & can be seen as & the results of the \\
\hline$\underline{\text { in addition to the }}$ & the beginning of the & it is important to & in the form of \\
\hline of this study is & at the time of & it should be noted & is assumed to be \\
\hline of this study was & English as a second & on the one hand & of the power system \\
\hline used in this study & as can be seen & can be found in & it is necessary to \\
\hline a positive effect on & the part of the & the ways in which & it is possible to \\
\hline the purpose of this & in addition to the & in other words the & the length of the \\
\hline
\end{tabular}


students were asked to

with respect to the

with regard to the

the degree to which

the use of technology

the effectiveness of the

the design of the

the content of the

this study was to

in the current study

in the present study

one of the most

in the use of

the other hand the

in relation to the

in the field of in the target language

the way in which

in the use of

in terms of their

in the course of

the students in the

in relation to the

one of the most

with respect to the

a small number of

the role of the

to the fact that

of the present study

as a foreign language

native speakers of English

the percent of the the other hand the

the starting point of

be seen as a

in the eyes of

the beginning of the

should be noted that

that there is a

at the level of

for the purpose of

in hong kong and

are more likely to

the meaning of the

on the part of

the purpose of the

a wide range of

the use of the

*1. Bundles underlined in educational technology are those shared with applied linguistics, electrical engineering or both fields.

**2. Bundles in bold in applied linguistics or electrical engineering are those shared with educational technology.

As can be observed from Table 6, the overlapping bundles that educational technology and applied linguistics share with each other contain less discipline-specific words but mostly serve the general purpose of academic writing or even general writing. This is illustrated by the bundles of on the other hand, the other hand the, at the same time, on the basis of, as a result of, in terms of the, as well as the, in addition to the, in relation to the, the extent to which, the beginning of the, the end of the, at the end of, in the context of, in the case of, it is important to, and so on. Applied linguists use these general-purpose bundles to perform a variety of functions essential to the organization of arguments, such as displaying the connection or the transition of text, directing readers to the organization of text, explaining causative relations between elements, noting a particular context or a referent, and weaving the thread of authorial argument. Extensively using these bundles in applied linguistics, as Hyland (2008b) argues, reflects "the more discursive and evaluative patterns of argument in the soft knowledge fields, where persuasion is more explicitly interpretative" (p.16).

The general-purpose bundles in electrical engineering, comparatively, are less frequently used; rather, most bundles in electrical engineering were found to refer to figures (e.g., as shown in figure, is shown in figure, as shown in fig, is shown in fig, are shown in figure, are shown in fig) and demonstrate a series of research/experiment-related aspects, such as model construction, material employment, procedure depiction or specification of physical 
environment (e.g., the size of the, the performance of the, the magnitude of the, the accuracy of the, the structure of the, a function of the, the length of the). Moreover, many bundles in electrical engineering are present in passive voice (e.g., is shown in figure, are shown in fig, is assumed to be, is given by equation, is defined as the, can be obtained by). These findings place a particular emphasis of authorial absence and human invisibility in scientific writing in electrical engineering, as opposed to educational technology.

In summary, the cross-discipline quantitative analyses of the number of different bundles and the structure of bundles unanimously show that educational technology sits at a close distance from applied linguistics but at a relatively long distance from electrical engineering. Qualitative analysis of the content of the bundles across three disciplines further suggests that educational technology adopts a similar discursive style to that by applied linguistics to frame writing. Synthesizing both quantitative and qualitative findings in the present study, it is possible to conclude that educational technology can be defined as a discipline more closely related to soft science than to hard science.

\section{Discussion and Conclusion}

"Academic writing is not a single undifferentiated mass, but a variety of subject-specific literacies" (Hyland, 2002, p.352). It not only conveys values and beliefs writers hold but also reflects the disciplinary nature within a particular academic community. This study, through the lens of academic literacies, investigates the features of lexical bundles in terms of frequency, content, and structural categories, with an aim to capture empirically the disciplinary nature of educational technology.

First, regarding the number of different bundles, researchers in educational technology tend to use as many lexical bundles as researchers in applied linguistics, business studies, and biology but a relatively smaller number of lexical bundles than researchers in electrical engineering. This result might imply that academics in the four disciplines of educational technology, applied linguistics, business studies, and biology use a more limited number of prefabricated linguistic patterns to develop their claims, compared with academics in electrical engineering who employ a wider variety of prefabricated patterns. Scrutinizing the content of the identified bundles demonstrates similarities and differences between educational technology and other disciplines. Educational technology has a fairly high overlap of bundle use with applied linguistics and business studies but a considerably low overlap with electrical engineering. Such a finding may suggest that academics in educational technology, applied linguistics, and business studies share a close affinity in framing arguments and constructing propositions in their disciplinary writing.

Second, the cross-discipline content analysis of the top 50 high-frequency bundles demonstrates that a large number of general-purpose bundles are shared by educational technology and applied linguistics. These shared general-purpose bundles are mostly "text-oriented bundles" (Hyland, 2008b, p. 13) (e.g., in addition to the, in relation to the, as well as the), ones that help organize the text, develop the structure of arguments, and make a link between discourse elements. In contrast, electrical engineering predominantly uses a myriad of "research-oriented bundles" (Chen \& Xiao, 2015; Hyland, 2008b, p. 13) (e.g., the 
magnitude of the, the accuracy of the, the structure of the, of the power system) for reporting scientific experiments and empirical research activity. This finding probably reflects a fact that educational technology, similar to soft science fields such as applied linguistics, appears to map arguments and disseminate knowledge in a discursively elaborate and interpretive manner (Hyland, 2004). In other words, a key feature shared by educational technology and applied linguistics is not simply how they report experimental activity and research results, but also how they give explanation and make plausible reasoning, suggesting that they may have different disciplinary nature and academic cultural norms from electrical engineering.

Third, concerning the structure of lexical bundles, noun phrase $+o f$, prepositional phrase $+o f$, other prepositional phrases, and other noun phrases are four structural categories extensively used in educational technology. Noun phrases and prepositional phrases are two essential elements constructing the building blocks of these lexical bundles. This result is in line with the findings of previous studies that whatever the disciplines, noun phrases and prepositional phrases are favorable structural units abounding in academic wiring (Breeze, 2013; Hyland, 2008b). Further exploration into the prevailing structural categories across disciplines suggests that the bundle structure of passive + prepositional phrase fragment is not frequently used in educational technology but makes a striking feature in electrical engineering and biology. Its high frequency in electrical engineering and biology might be closely related to the prevalence of passive voice in hard science. Passive voice has been notably preferred and considered a tradition in scientific papers since it helps underscore the centrality of technical content in natural science and engineering research as well as the importance of objectivity in hard science studies (Plotnick, n.d.). More specifically, by obscuring or diminishing the agent of the action, passive voice helps create an objective picture of reality and reflect the nature of non-human intervention in hard science. The frequency of passive bundles in educational technology does not constitute such a high proportion as that in electrical engineering and biology. This finding may provide another supportive evidence to position educational technology as a field not so closely related to hard science as the word "technology" may suggest.

Differences in the use of lexical bundles between educational technology and electrical engineering may be somewhat elucidated by the notions of people and technology. Technology, from the perspective of engineers, typically refers to machines, computer devices, technical equipment, electronic tools, physical systems, and hardware aspects (Luppicini, 2005). Comparatively, educational technologists view technology as intellectual processes that systematically apply scientific knowledge to attain educational goals (Januszewski \& Molenda, 2008). It is not merely material construction itself but socially constructed and intellectually shaped (Lakhana, 2014; Luppicini, 2005). Educational technologists are not devoted to making technological design but to selecting and evaluating technological processes and resources in order to enhance the effectiveness and efficiency of instruction (Hlynka \& Jacobsen, 2009). Such a distinction in the conception of technology probably influences the linguistic realization of lexical bundles. Analyses of the number of different bundles, the content of bundles, and the structure of bundles all demonstrate that educational technology characterizes soft technology and exhibits a considerable interplay 
between human contexts and technology use.

In conclusion, the cross-disciplinary comparison of lexical bundles suggests that educational technology may be more inclined to soft science fields in terms of the number of different bundles, the content of bundles, and the syntactic structure of bundles. In other words, the use of bundles can reveal the underlying nature of educational technology as the contemporary conception suggests. This study provides empirical value to complement existing research, enlightening our understanding of the disciplinary nature and orientation of educational technology. Nevertheless, this study is exploratory in nature and more evidence related to disciplinary findings is required to consolidate the conclusion. Future research on a more comprehensive cross-disciplinary investigation is recommended to derive a more robust conclusion.

As a corpus-informed study, the present study provides very practical pedagogical value. The generated frequent lexical bundles are helpful for designing specialized courses for educational technology, particularly beneficial for novice researchers who struggle to meet the expectations of disciplinary writing conventions and endeavor to establish a proper link to the disciplinary discourse community. Pedagogical applications may include such activities as comparing the usage of lexical bundles generated by novices with that in the bundle list or conducting a concordance analysis to examine how the identified lexical bundles are contextualized. Familiarization of lexical bundles through these activities enables individuals to raise linguistic awareness of academic writing and advance to a more competent participator in the disciplinary community

\section{Acknowledgements}

The researcher is deeply indebted to the editor and two anonymous reviewers for their insightful comments on this article. The researcher is also grateful to Prof. Chih-Hua Kuo, Prof. Wei-Ming Luh, and Prof. Ya-Ting Carolyn Yang for their highly constructive feedback on earlier versions of the article.

\section{References}

Ajelabi, A. (2006). Essentials of educational technology. Lagos: Raytel Communications Limited.

Alipour, M., \& Zarea, M. (2013). A disciplinary study of lexical bundles: The case of native versus non-native corpora. Taiwan International ESP Journal, 5(2), 1-20.

Anthony, L. (2014). AntConc (Version 3.4. 3)[Computer Software]. Tokyo, Japan: Waseda University. Retrieved from http://www.laurenceanthony.net/software/antconc/

Association for Educational Communications and Technology (1977). Educational technology: Definition and glossary of terms. Washington DC: Association for Educational Communications and Technology.

Association for Educational Communications and Technology (2008). Definition. In A. Januszewski, \& M. Molenda (Eds.), Educational technology: A definition with commentary. 
New York: Lawrence Erlbaum Associates.

Becher, T., \& Trowler, P. (2001). Academic tribes and territories: Intellectual enquiry and the culture of disciplines. Buckingham: Open University Press.

Biber, D., \& Barbieri, F. (2007). Lexical bundles in university spoken and written registers. English for Specific Purposes, 26(3), 263-286. https://doi.org/10.1016/j.esp.2006.08.003

Biber, D., Conrad, S., \& Cortes, V. (2004). If you look at...: lexical bundles in university teaching and textbooks. Applied Linguistics, 25(3), 371-405. https://doi.org/10.1093/applin/25.3.371

Biber, D., Johansson, S., Leech, G., Conrad, S., \& Finegan, E. (1999). Longman grammar of spoken and written English. Harlow: Pearson.

Breeze, R. (2013). Lexical bundles across four legal genres. International Journal of Corpus Linguistics, 18(2), 229-253. http://doi.org/10.1075/ijcl.18.2.03bre

Chen, Y.-H., \& Baker, P. (2010). Lexical bundles in L1 and L2 academic writing. Language Learning \& Technology, 14(2), 30-49.

Chen, X., \& Xiao, G. (2015). A Corpus-based Study of the Structures and Functions of Academic Chunks in the Discipline of Engineering. In Proceedings of the 5th International Conference on Information Engineering for Mechanics and Materials (pp. 1328-1332). Huhhot, Inner Mongolia: Atlantis Press. https://doi.org/10.2991/icimm-15.2015.241

Corbeil, J. R., \& Corbeil, M. E. (2013). What do educational technologists do? The discipline as defined by educational technology practitioners Issues in Information Systems, 14(2), 336-345.

Cortes, V. (2004). Lexical bundles in published and student disciplinary writing: Examples from history and biology. English for Specific Purposes, 23(4), 397-423. http://doi.org/10.1016/j.esp.2003.12.001

Csomay, E. (2013). Lexical bundles in discourse structure: A corpus-based study of classroom discourse. Applied Linguistics, 34(3), 369-388. http://doi.org/10.1093/applin/ams045

Czerniewicz, L. (2010). Educational technology-Mapping the terrain with Bernstein as cartographer. Journal of Computer Assisted Learning, 26(6), 523-534. http://doi.org/10.1111/j.1365-2729.2010.00359.x

Davies, I. K., \& Schwen, T. M. (1971). Toward a definition of instructional development. Washington: AECT.

Demirel, E. T., \& Hesamoddin, S. A. (2013). Lexical bundles in research article acknowledgments: A corpus comparison. Hacettepe University Journal of Education, 28(2), 457-468.

Ellington, H., Percival, F., \& Race, P. (1993). A handbook of educational technology. London: 


\section{Macrothink}

Kogan Page.

Erman, B., \& Warren, B. (2000). The idiom principle and the open choice principle. Text, 20(1), 29-62. http://doi.org/10.1515/text.1.2000.20.1.29

Gotti, M. (2009). Commonality and individuality in academic discourse. Bern: Peter Lang.

Grabowski, Ł. (2015). Keywords and lexical bundles within English pharmaceutical discourse: A corpus-driven description. English for Specific Purposes, 38, 23-33. http://doi.org/10.1016/j.esp.2014.10.004

Granger, S. (1998). Prefabricated patterns in advanced EFL writing: Collocations and lexical phrases. In A. P. Cowie (Ed.), Phraseology: Theory, analysis and applications (pp. 145-160). Oxford: Clarendon Press.

Hlynka, D., \& Jacobsen, M. (2009). What is educational technology, anyway? A commentary on the new AECT definition of the field. Canadian Journal of Learning and Technology, 35(2). Retrieved from https://www.cjlt.ca/index.php/cjlt/article/view/26395/19577 http://dx.doi.org/10.21432/T2N88P

Hyland, K. (2002). Options of identity in academic writing. ELT journal, 56(4), 351-358. http://doi.org/10.1093/elt/56.4.351

Hyland, K. (2004). Disciplinary interactions: Metadiscourse in L2 postgraduate writing. Journal of Second Language Writing, 13(2), 133-151. http://doi.org/10.1016/j.jslw.2004.02.001

Hyland, K. (2008a). Academic clusters: Text patterning in published and postgraduate writing. International Journal of Applied Linguistics, 18(1), 41-62. http://doi.org/10.1111/j.1473-4192.2008.00178.x

Hyland, K. (2008b). As can be seen: Lexical bundles and disciplinary variation. English for Specific Purposes, 27(1), 4-21. http://doi.org/10.1016/j.esp.2007.06.001

Jalali, H. (2014). A comparative study of anticipatory it lexical bundles in applied linguistics and analytical chemistry research articles. Journal of Foreign Language Teaching and Translation Studies, 3(1), 24-42.

Jalali, H., Eslami Rasekh, A., \& Tavangar Rizi, M. (2008). Lexical bundles and intradisciplinary variation: The case of applied linguistics. Iranian journal of language studies, 2(4), 447-484.

Jalali, Z. S., Moini, M. R., \& Arani, M. A. (2015). Structural and functional analysis of lexical bundles in medical research articles: A corpus-based study. International Journal of Information Science and Management (IJISM), 13(1), 51-69.

Januszewski, A., \& Molenda, M. (2008). Educational technology: A definition with commentary. New York: Routledge.

Kashiha, H., \& Heng, C. S. (2014a). Discourse functions of formulaic sequences in academic 
speech across two disciplines. GEMA Online Journal of Language Studies, 14(2), 15-27. http://doi.org/10.17576/GEMA-2014-1402-02

Kashiha, H., \& Heng, C. S. (2014b). Structural analysis of lexical bundles in university lectures of politics and chemistry. International Journal of Applied Linguistics and English Literature, 3(1), 224-230. http://doi.org/10.7575/aiac.ijalel.v.3n.1p.224

Lakhana, A. (2014). What is Educational Technology? An Inquiry into the Meaning, Use, and Reciprocity of Technology. Canadian Journal of Learning \& Technology, 40(3), 1-41. http://doi.org/10.21432/T2H59S

Latchem, C. (2014). BJET Editorial: Opening up the educational technology research agenda. British Journal of Educational Technology, 45(1), 3-11. http://doi.org/10.1111/bjet.12122

Li, J., \& Schmitt, N. (2009). The acquisition of lexical phrases in academic writing: A longitudinal case study. Journal of Second Language Writing, 18(2), 85-102. http://doi.org/10.1016/j.jslw.2009.02.001

Liu, D. (2012). The most frequently-used multi-word constructions in academic written English: A multi-corpus study. English for Specific Purposes, 31(1), 25-35. http://doi.org/10.1016/j.esp.2011.07.002

Loveland, T. (2012). Educational technology and technology education. In P. J. Williams (Ed.), Technology education for teachers (pp. 115-136). Rotterdam: Sense Publishers. https://doi.org/10.1007/978-94-6209-161-0_6

Luppicini, R. (2005). A systems definition of educational technology in society. Journal of Educational Technology \& Society, 8(3), 103-109.

Luppicini, R. (2008). Educational technology at a crossroads: Examining the development of the academic field in Canada. Journal of Educational Technology \& Society, 11(4), 281-296.

Mangal, S. K., \& Mangal, U. (2009). Essentials of educational technology. New Delhi, India: PHI Learning Private Limited.

McGinn, R. E. (1978). What is technology. Research in Philosophy and Technology, 1(1), 179-197.

Newby, T. J., Stepich, D. A., Lehman, J. D., \& Russell, J. D. (2006). Educational technology for teaching and learning (3rd ed.). Upper Saddle River, New Jersey: Pearson

Oliver, M. (2011). Technological determinism in educational technology research: Some alternative ways of thinking about the relationship between learning and technology. Journal of Computer Assisted Learning, 373-384. http://dx.doi.org/10.1111/j.1365-2729.2011.00406.x

Pawley, A., \& Syder, F. H. (1983). Two puzzles for linguistic theory: Native like selection and nativelike fluency. In J. R. R. Schmidt (Ed.), Language and communication (Vol. 191, pp. 191-226). Longman: London Press. 


\section{Macrothink}

Education and Linguistics Research

ISSN 2377-1356 2017, Vol. 3, No. 1

Plotnick, J. (n.d.) Writing in the Sciences. Retrieved October 5, 2015, from http://www.writing.utoronto.ca/advice/specific-types-of-writing/science

Rayson, P. (2008). From key words to key semantic domains. International Journal of Corpus Linguistics, 13(4), 519-549. http://doi.org/10.1075/ijcl.13.4.06ray

Reiser, R. A. (2012). What field did you say you were in? In R. Reiser, \& J. Dempsey (Eds.), Trends and issues in instructional design and technology (pp. 1-7). Boston, MA: Pearson.

Selwyn, N. (2007). The use of computer technology in university teaching and learning: a critical perspective. Journal of Computer Assisted Learning, 23(2), 83-94. http://doi.org/10.1111/j.1365-2729.2006.00204.x

Selwyn, N. (2010). Looking beyond learning: Notes towards the critical study of educational technology. Journal of Computer Assisted Learning, 26(1), 65-73. http://dx.doi.org/10.1111/j.1365-2729.2009.00338.x

Simpson-Vlach, R., \& Ellis, N. C. (2010). An academic formulas list: New methods in $\begin{array}{llll}\text { phraseology } \quad \text { research. } & \text { Applied } & \text { Linguistics, } & 31(4),\end{array}$ http://dx.doi.org/10.1093/applin/amp058

Spector, J. M., Johnson, T. E., \& Young, P. A. (2014). An editorial on research and development in and with educational technology. Educational Technology Research and Development, 62(1), 1-12. http://doi.org/10.1007/s11423-014-9331-z

Stubbs, M. (2007). An example of frequent English phraseology: Distributions, structures and functions. Language and Computers, 62(1), https://doi.org/10.1163/9789401204347_007

Wei, Y., \& Lei, L. (2011). Lexical bundles in the academic writing of advanced Chinese EFL learners. RELC Journal, 42(2), 155-166. http://doi.org/10.1177/0033688211407295 


\section{Macrothink

\section{Appendix}

Appendix 1. Four-word Lexical Bundles in Educational Technology RAs

\begin{tabular}{|c|c|c|c|}
\hline Rank & Frequency & Range & Lexical Bundle \\
\hline 1 & 314 & 154 & on the other hand \\
\hline 2 & 236 & 123 & the results of the \\
\hline 3 & 222 & 103 & at the end of \\
\hline 4 & 213 & 111 & the end of the \\
\hline 5 & 209 & 98 & the use of the \\
\hline 6 & 205 & 130 & as well as the \\
\hline 7 & 190 & 114 & in the context of \\
\hline 8 & 168 & 66 & the students in the \\
\hline 9 & 165 & 110 & at the same time \\
\hline 10 & 154 & 99 & in the form of \\
\hline 11 & 151 & 75 & as shown in table \\
\hline 12 & 143 & 89 & in terms of the \\
\hline 13 & 131 & 77 & as a result of \\
\hline 14 & 129 & 82 & the results of this \\
\hline 15 & 128 & 61 & on the basis of \\
\hline 16 & 127 & 89 & it is important to \\
\hline 17 & 124 & 83 & can be used to \\
\hline 18 & 116 & 80 & in this study the \\
\hline 19 & 110 & 62 & the extent to which \\
\hline 20 & 109 & 61 & the beginning of the \\
\hline 21 & 107 & 67 & results of this study \\
\hline 22 & 103 & 65 & at the beginning of \\
\hline 23 & 99 & 53 & in the case of \\
\hline 24 & 98 & 65 & that the use of \\
\hline 25 & 98 & 59 & the quality of the \\
\hline 26 & 98 & 60 & to the use of \\
\hline 27 & 96 & 65 & on the use of \\
\hline 28 & 94 & 65 & to be able to \\
\hline 29 & 91 & 69 & in addition to the \\
\hline
\end{tabular}


$30 \quad 90$

69

$31 \quad 90$

67

32

89

58

$33 \quad 88$

32

$34 \quad 88$

$35 \quad 87$

$36 \quad 87$

37

85

38

84

$39 \quad 84$

$40 \quad 83$

$41 \quad 80$

$42 \quad 79$

$43 \quad 78$

$44 \quad 76$

$45 \quad 76$

$46 \quad 75$

$47 \quad 73$

$48 \quad 73$

$49 \quad 72$

$50 \quad 72$

$51 \quad 72$

$52 \quad 72$

$53 \quad 72$

$54 \quad 71$

$55 \quad 71$

$56 \quad 70$

$57 \quad 70$

$58 \quad 70$

$59 \quad 69$

$60 \quad 69$

61
66

57

49

42

39

48

59

55

52

61

37

45

59

50

56

49

37

39

39

50

45

44

43

45

59

41

54

42 of this study is

of this study was

used in this study

a positive effect on

the purpose of this

students were asked to

with respect to the

with regard to the

the degree to which

the use of technology

the effectiveness of the

the design of the

the content of the

this study was to

in the current study

in the present study

one of the most

in the use of

the other hand the

in relation to the

in the field of

it was found that

the total number of

through the use of

are more likely to

the results showed that

as shown in figure

in this paper we

to participate in the

are shown in table

purpose of this study

of the use of 
62

63

64

65

66

67

68

69

70

71

72

73

74

75

76

77

78

79

80

81

82

83

84

85

86

87

88

89

90

91

92

93
68

50

48

46

54

56

49

40

46

49

49

39

35

45

48

33

52

43

44

39

37

34

40

46

38

38

33

36

41

39

39

49

41

the nature of the

to the fact that

in the process of

is one of the

the fact that the

in other words the

the role of the

in a way that

the purpose of the

the rest of the

for each of the

for teaching and learning

as part of the

the use of $a$

in teaching and learning

in this study was

in this study we

is based on the

participants were asked to

of teaching and learning

the effect of the

the majority of the

for the purpose of

in the learning process

of the present study

the implementation of the

it should be noted

the development of the

in terms of their

there is a need

a wide range of

information and communication technology 


\begin{tabular}{|c|c|c|c|}
\hline 94 & 54 & 39 & that there was a \\
\hline 95 & 54 & 44 & this study is to \\
\hline 96 & 53 & 39 & as well as to \\
\hline 97 & 53 & 37 & on the one hand \\
\hline 98 & 53 & 40 & that can be used \\
\hline 99 & 53 & 42 & with the use of \\
\hline 100 & 52 & 37 & a higher level of \\
\hline 101 & 52 & 39 & and the use of \\
\hline 102 & 52 & 36 & were randomly assigned to \\
\hline 103 & 51 & 40 & for the development of \\
\hline 104 & 51 & 36 & in the design of \\
\hline 105 & 51 & 37 & it is necessary to \\
\hline 106 & 50 & 40 & in the development of \\
\hline 107 & 50 & 36 & the development of a \\
\hline 108 & 49 & 37 & in line with the \\
\hline 109 & 49 & 33 & should be noted that \\
\hline 110 & 49 & 37 & within the context of \\
\hline 111 & 48 & 42 & has the potential to \\
\hline 112 & 48 & 41 & in this study were \\
\hline 113 & 48 & 32 & participated in the study \\
\hline 114 & 48 & 32 & the results show that \\
\hline 115 & 47 & 38 & of the students in \\
\hline 116 & 47 & 37 & that there is a \\
\hline 117 & 46 & 42 & an important role in \\
\hline 118 & 46 & 38 & it is possible to \\
\hline 119 & 46 & 38 & the context of the \\
\hline 120 & 46 & 32 & was found to be \\
\hline 121 & 45 & 39 & in the next section \\
\hline 122 & 45 & 33 & the results indicate that \\
\hline 123 & 44 & 32 & a better understanding of \\
\hline 124 & 44 & 36 & a result of the \\
\hline 125 & 44 & 34 & the analysis of the \\
\hline
\end{tabular}




\section{Macrothink

\section{Copyright Disclaimer}

Copyright reserved by the author(s).

This article is an open-access article distributed under the terms and conditions of the Creative Commons Attribution license (http://creativecommons.org/licenses/by/3.0/). 